\title{
Reliability and clinical relevance of detection of vegetations by echocardiography in bacterial endocarditis ${ }^{\star}$
}

\author{
ANDREW J HICKEY, JANE WOLFERS, DAVID E L WILCKEN · \\ From The Department of Medicine, The Prince Henry Hospital, Sydney, NSW, Australia
}

SUMMARY The efficacy of M-mode echocardiography in identifying vegetations and the clinical relevance of such a finding were evaluated in 36 patients with bacterial endocarditis, 18 of whom had pre-existing valvar lesions. Of 22 patients with vegetations demonstrated by echocardiography, 21 had major complications of bacterial endocarditis and eight died, whereas only eight of the 14 patients without detectable vegetations had similar complications and only two died. Nine of the 11 patients with pre-existing valvar lesions and echocardiographic evidence of vegetations came to operation or necropsy, and in eight of these the presence of vegetations was confirmed. In the other, none was found at surgery performed after an interval of six months. M-mode echocardiography can reliably detect vegetations in patients with bacterial endocarditis even in the presence of pre-existing valvar lesions, and may permit the identification of a subset of high risk patients who may need early surgery.

The use of motion or M-mode echocardiography to detect vegetations on the heart valves of patients with infective endocarditis was first described by Dillon $e t$ $a l$. in $1972 .^{1}$ Several studies used this observation to identify a high risk group. ${ }^{2-4}$ Controversy still exists, however, concerning the value of this observation. In this study we report our experience with $M$-mode echocardiography in 36 patients with infective endocarditis. Emphasis is given to defining a high risk group. Though the reliability of echocardiography to detect vegetations has been assessed, ${ }^{56}$ the reliability of this observation in the presence of pre-existing valvar lesions has not. Our study investigates this problem.

\section{Patients and methods}

The clinical histories and echocardiograms of all patients who had infective endocarditis between January 1976 and June 1980 were reviewed. All patients who had substantial evidence of endocarditis, with or without a positive blood culture, and in whom a good quality $M$-mode echocardiogram was recorded, were considered (Fig 1 and 2). Those with endocarditis on non-tissue prosthetic valves and those with endocarditis secondary to a terminal illness were excluded. Thirty-six patients met these criteria. There were 23

\footnotetext{
* Supported by The National Health and Medical Research Council of Australia.
} Received for publication 30 June 1981 males and 13 female patients of average age 20.25 years (range 2 to 90 years). All echocardiograms were recorded using an Ultrasonics Institute echocardiograph attached to a Honeywell fibreoptic recorder. A two-megaHertz transducer was used and a standard M-mode echocardiogram was recorded in each case. ${ }^{7}$

Criteria adopted for diagnosis of vegetations at echocardiography were the detection of echoes indicating shaggy non-uniform masses with and without restriction of leaflet motion. When evidence of a preexisting valve lesion was present at echocardiography the left atrium in the case of the mitral valve and the left ventricular outflow tract when the aortic valve was affected were examined to detect the appearance of these non-uniform echoes. Two observers analysed the echocardiograms independently. Total agreement occurred in all but five cases; in these a diagnosis of probable vegetations was made.

\section{Results}

Two groups of patients were recognised on the basis of the presence or absence of vegetations at echocardiography. There were 22 patients with vegetations detected, 17 of these definitely and five probably. Fourteen did not have demonstrable vegetations. Table 1 is a comparison of the incidence of complications in these two groups.

Both groups of patients were followed up for 


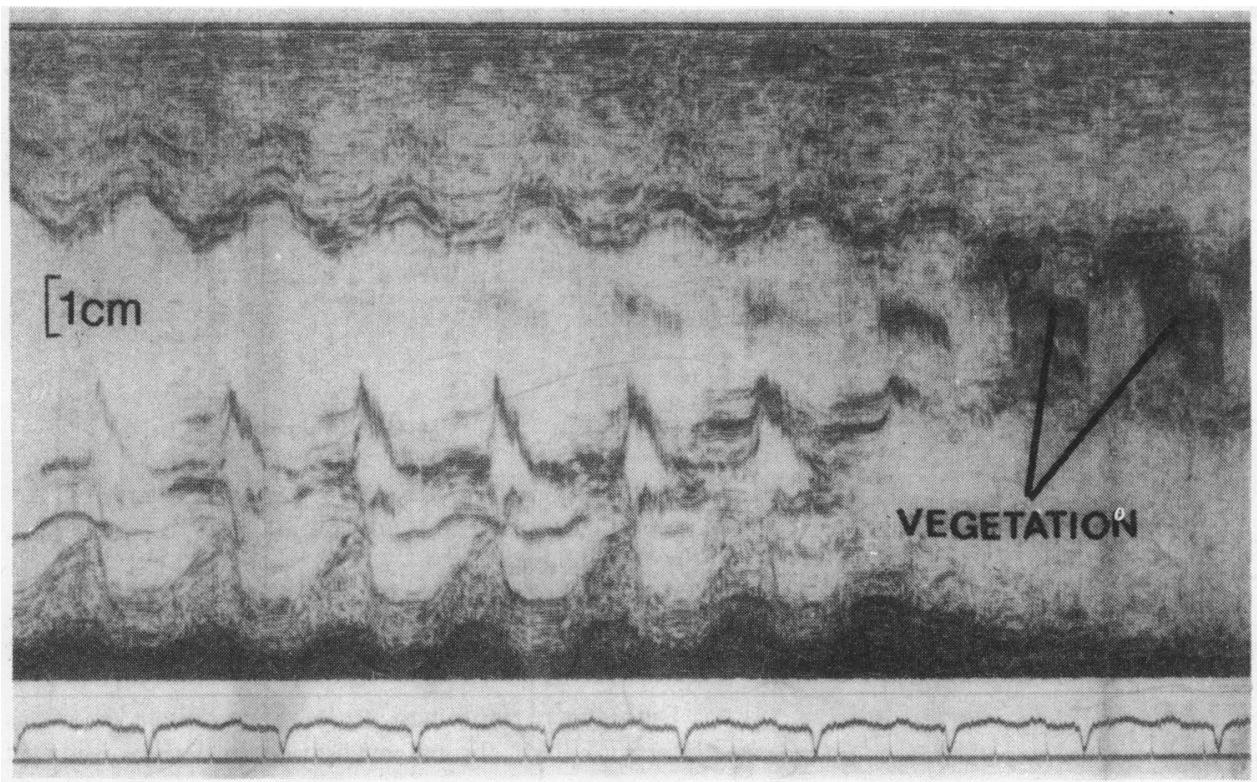

Fig. $1 M$-mode echocardiogram of scan from aorta to left ventricle with vegetations on the aortic valve which prolapse into| the left ventricular outflow tract. This was confirmed at surgery.

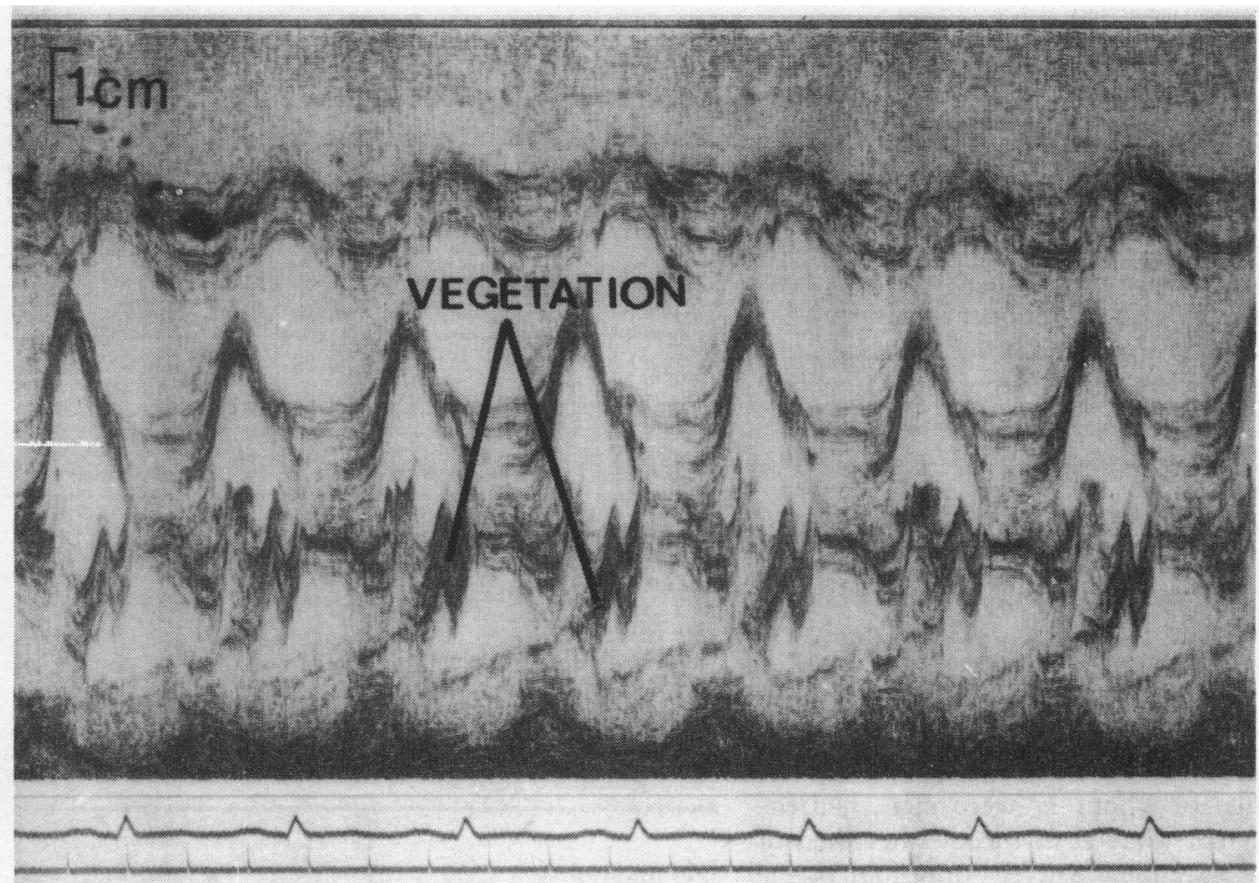

Fig. $2 M$-mode echocardiogram of mitral valve with vegetations attached to the posterior leaflet. This was also confirmed at surgery. 
Table 1 Comparison of complications in both groups of patients with and without vegetations

\begin{tabular}{lll}
\hline & $\begin{array}{l}\text { Patients with } \\
\text { vegetations detected } \\
\text { by echocardiography } \\
N=22^{\star}\end{array}$ & $\begin{array}{l}\text { Patients without } \\
\text { vegetations detected } \\
\text { by echocardiography } \\
n=14\end{array}$ \\
\hline $\begin{array}{l}\text { Complications } \\
\text { Congestive cardiac } \\
\text { failure }\end{array}$ & 18 & \\
Emboli & 11 & 4 \\
Valve replacement & 14 & 5 \\
Death & 8 & 3 \\
No complications & 1 & 2 \\
\hline
\end{tabular}

$\star$ Definite vegetations $=17$; probable 5 .

periods ranging from one week (early death) to two years. The patients with detectable vegetations had an average follow up period of 28 weeks and those without vegetations 18 weeks. In the group with vegetations, shown by echo cardiography, death, embolism, and/or cardiac failure occurred in $95 \%$. In the group without documented vegetations these complications were found in $57 \%$. Fourteen $(64 \%)$ of the 22 patients with detectable vegetations required valve replacement because of intractable cardiac failure; surgery was performed during the acute phase of the illness, that is within six weeks of starting antibiotic treatment. In contrast, only three $(21 \%)$ of the 14 patients without detectable vegetations required valve replacement and only one of these needed urgent surgery. In addition, eight of the 22 patients with detectable vegetations ( $36 \%$ ) died compared with two of the 14 patients without detectable vegetations (14\%). Three of the former died before planned surgery could be undertaken; two died from septicaemic shock and one from acute myocardial infarction (possibly resulting from a coronary embolus). Six patients, four with vegetations at echocardiography and two without, died either at operation or within three months of operation. The remaining patient with vegetations at echocardiography who died had a cerebral embolus six months after discharge from hospital. This patient had not had previous emboli or cardiac failure.

The clinical features of the high risk group of patients with vegetations at echocardiography were compared with the group in whom vegetations were not identified (Table 2). The former patients were usually older men with endocarditis of the aortic valve who had a longer duration of symptoms. Twenty-one of the 36 patients, of whom 17 were men, had the aortic valve affected. Sixteen of these either died or required valve replacement whereas only four of the 11 patients with isolated mitral valve endocarditis had a similar outcome. There was no difference between the two groups in the incidence of pre-existing valvar
Table 2 Clinical features of patients with and without vegetations detected at echocardiography

\begin{tabular}{|c|c|c|}
\hline & $\begin{array}{l}\text { Patients with } \\
\text { vegetations detected } \\
\text { by echocardiography } \\
N=22\end{array}$ & $\begin{array}{l}\text { Patients without } \\
\text { vegetations detected } \\
\text { by echocardiography } \\
N=14\end{array}$ \\
\hline $\begin{array}{l}\text { Mean duration of } \\
\text { symptoms before } \\
\text { diagnosis }\end{array}$ & $6 \mathrm{wk}$ & 4 wk \\
\hline Age (years) & 48.8 & 34.5 \\
\hline Sex ratio $(M / F)$ & $17: 5$ & $7: 7$ \\
\hline $\begin{array}{l}\text { Pre-existing valvar } \\
\text { lesions }\end{array}$ & 11 & 7 \\
\hline Valves affected & $\begin{array}{l}\text { Aortic } 18 \\
\text { Mitral } 6\end{array}$ & $\begin{array}{l}\text { Aortic } 3 \\
\text { Mitral } 7 \\
\text { Tricuspid } 2 \\
\text { CHD } 2\end{array}$ \\
\hline
\end{tabular}

${ }^{\star} \mathrm{CHD}$ congenital heart disease.

lesions (Table 2) or in the organisms identified (Table 3).

Eighteen patients had pre-existing valvar lesions as determined by clinical evaluation and thickening of valve cusps documented at echocardiography. Eleven of these were considered to have vegetations. In nine of these 11 patients tissue was obtained at surgery or necropsy, and an echocardiographic finding of vegetations was confirmed in eight of the nine. The one false positive diagnosis was in a patient with a thickened aortic valve in whom no vegetations were found at surgery performed six months later. One false negative was in a patient without evidence of a pre-existing valve lesion in whom multiple small vegetations, each approximately $1 \mathrm{~mm}$ in diameter, were found during surgery for valve replacement.

Table 3 Comparison of organisms grown in patients with and without echocardiographically detected vegetations

\begin{tabular}{lll}
\hline & $\begin{array}{l}\text { Patients with } \\
\text { vegetations } \\
\text { detected by } \\
\text { echocardiography } \\
N=22\end{array}$ & $\begin{array}{l}\text { Patients without } \\
\text { vegetations } \\
\text { detected by } \\
\text { echocardiography } \\
N=14\end{array}$ \\
\hline $\begin{array}{ll}\text { Organisms cultured } \\
\text { Streptococcus viridans }\end{array}$ & 7 & \\
Staphylococcus aureus & 5 & 5 \\
Staphylococcus albus & 3 & 4 \\
Streptococcus pyogenes & 1 & 0 \\
Streptococcus faecalis & 2 & 1 \\
Streptococcus bovis & 0 & 0 \\
Haemophilus influenza & 0 & 1 \\
No organisms cultured 4 & 1 \\
\hline
\end{tabular}

\section{Discussion}

Our retrospective study using M-mode echocardiography in infective endocarditis indicates that 
the detection of vegetations identifies a high risk group with a much increased incidence of serious complications (major emboli and/or cardiac failure) leading to valve replacement or death. This technique was sensitive in detecting vegetations in patients with pre-existing valvar lesions.

The reported incidence of grave complications in patients with vegetations detected at echocardiography has varied widely. In a study of 65 patients with endocarditis Wann et al. ${ }^{2}$ found that 22 of them had vegetations at echocardiography. Twenty of these either died or underwent valve replacement during their stay in hospital. None of the patients without vegetations at echocardiography required surgery or died as a result of cardiac disease. Davis et al ${ }^{3}$ in a similar study of 30 patients with infective endocarditis noted that patients with vegetations at echocardiography had a significantly increased incidence of congestive cardiac failure, major emboli, and need for valve replacement. In fact all of their 17 patients with vegetations at echocardiography required valve replacement, 16 urgently and one electively. In contrast to these reports Stewart et al. ${ }^{4}$ noted a much lower incidence of these events occurring in their 47 patients with vegetations at echocardiography. Only 12 of these required valve replacements, and the incidence of serious complications was lower (30\%).

The major difference between these studies was the use of two-dimensional echocardiography in the study of Stewart et al. ${ }^{4}$ as opposed to M-mode echocardiography in the other two. ${ }^{23}$ Perhaps the sensisitivity of the two-dimensional system is such that it detects a larger array of sizes of vegetations in different sites which are inaccessible to $M$-mode echocardiography. There is, however, conflicting evidence concerning the relative sensititivities of $M$-mode and two-dimensional echocardiography in detecting vegetations. ${ }^{8} 9$ Wann et al. ${ }^{8}$ found no difference while Martin et al. ${ }^{9}$ reported the latter to be more sensitive.

The lack of sensitivity of $\mathrm{M}$-mode echocardiography in detecting vegetations has been discussed by Thomson et al..$^{5}$ who correctly identified vegetations in only eight of 16 heart valves later found to have vegetations either at surgery or at necropsy. They suggested that low sensitivity was in part a consequence of the high incidence of thickened and disorganised valves caused by pre-existing leaions (35\% of their patients). It is, therefore, important to assess the reliability of M-mode echocardiography in detecting vegetations in this situation. Eleven of our patients who had pre-existing valvar lesions were also considered to have vegetations at echocardiography. The affected valves of nine of these patients were visualised directly at surgery or at necropsy. The diagnosis was confirmed in eight. There was one false positive; this patient had myxomatous changes in the aortic valve with prolapse of one leaflet into the left ventricular outflow tract. Of the remaining two patients with vegetations at echocardiography with pre-existing abnormality of valves, one died and necropsy was refused; the other is alive and well and has not required surgery. Thus, in eight of the 11 patients with echocardiographically documented vegetations and pre-existing valvar lesions, the diagnosis was confirmed, suggesting that the presence of the latter does not affect the reliability of the method.

It is agreed that the detection of vegetations at echocardiography is not in itself an indication for valve replacement, ${ }^{24}$ but one of our patients who had an uncomplicated clinical course with bacteriological cure died of a cerebral embolus six months after discharge from hospital. In addition, Correll et al. ${ }^{10}$ in a post-mortem study of 70 patients with endocarditis noted that all deaths from embolic phenomena, uncomplicated by heart failure, occurred in patients with partially healed vegetations. Partial healing was defined as persistence of bacteria and polymorphonuclear leucocytes at microscopy, with failure of endothelialisation of the vegetations. Though it has been shown that morphology, size, and site of vegetations as detected at two-dimensional echocardiography correlate poorly with the occurence of emboli, ${ }^{4}$ Stafford $e t$ al. ${ }^{11}$ have noted in a study of six patients followed over an average period of 50 weeks, that echoes from vegetations which 'heal' become smaller and more reflective. It will require the follow-up of a larger group of patients to determine whether echocardiography with standardisation of transducer position and angulation and of gain settings as recommended by Stafford et al. ${ }^{11}$ can differentiate between partially healed and healed vegetations.

The present study shows that by demonstrating the presence of vegetations, M-mode echocardiography identifies a high risk group of patients with infective endocarditis.

This work was supported by the National Health and Medical Research Council of Australia.

\section{References}

1 Dillon JC, Feigenbaum H, Konecke LL, Davis RH, Chang S. Echocardiographic manifestations of valvular vegetations. Am Heart $\mathcal{F}$ 1973; 86: 698-704.

2 Wann LS, Dillon JC, Weyman AE, Feigenbaum H. Echocardiography in bacterial endocarditis. $N E n g l f$ Med 1976; 295: 135-9.

3 Davis RS, Strom JA, Frishman W, et al. The demonstration of vegetations by echocardiography in bacterial endocarditis: an indication for early surgical intervention. Am f Med 1980; 69: 57-63.

4 Stewart JA, Silimperi D, Harris P, Wise NK, Fraker 
TD, Jr, Kissolo JA. Echocardiographic documentation of vegetative lesions in infective endocarditis: clinical implications. Circulation 1980; 61: 374-80.

5 Thomson KR, Nanda NC, Gramiak R. The reliability of echocardiography in the diagnosis of infective endocarditis. Radioology 1977; 125: 473-6.

6 Strom J, Becker R, Davis R, et al. Echocardiographic and surgical correlations in bacterial endocarditis. Circulation 1980; 62, suppl 1: 164-7.

7 Feigenbaum H. Echocardiography. Philadelphia: Lea and Febiger, 1972.

8 Wann LS, Hallam CC, Dillon JC, Weyman AE, Feigenbaum $\mathrm{H}$. Comparison of $\mathrm{M}$-mode and cross-sectional echocardiography in infective endocarditis. Circulation 1979; 60: 728-33.
9 Martin RP, Meltzer RS, Chia BL, et al. Clinical utility of two-dimensional echocardiography in infective endocarditis. Am f Cardiol 1980; 46: 379-85.

10 Correll HL, Lubitz JM, Lindert MCF. Bacterial endocarditis: clinico-pathologic studies of unaltered, treated and cured patients. Ann Intern Med 1951; 35: 45-58.

11 Stafford A, Wann LS, Dillon JC, Weyman AE, Feigenbaum $\mathrm{H}$. Serial echocardiographic appearance of healing bacterial vegetations. Am f Cardiol 1979; 44: 754-60.

Requests for reprints to Dr D E L Wilcken, Department of Medicine, The Prince Henry Hospital, Little Bay, New South Wales, Australia. 